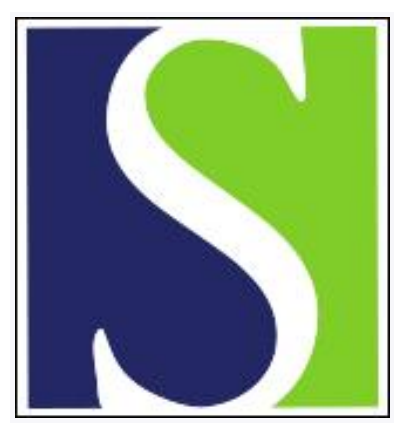

Scand J Work Environ Health 1998;24(3):220-227

https://doi.org/10.5271/sjweh.302

Issue date: Jun 1998

Antibody responses of rats after immunization with organic acid anhydrides as a model of predictive testing

by Zhang $X-D$, Welinder $H$, Jönsson BAG, Skerfving $S$

The following articles refer to this text: 2001;27(2):133-139;

2001;27(5):327-334

Key terms: animal model; immunoglobulin E; immunoglobulin G; occupational allergy; structure-activity relationship

This article in PubMed: www.ncbi.nlm.nih.gov/pubmed/9710375

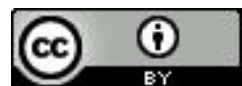




\title{
Antibody responses of rats after immunization with organic acid anhydrides as a model of predictive testing
}

\author{
by Xing-Dong Zhang, MD, ${ }^{1}$ Hans Welinder, PhD, ${ }^{1}$ Bo AG Jönsson, PhD, ${ }^{1}$ Staffan Skerfving, MD
}

\begin{abstract}
Zhang X-D, Welinder $H$, Jönsson BAG, Skerfving $S$. Antibody responses of rats after immunization with organic acid anhydrides as a model of predictive testing. Scand J work Environ Health 1998;24(3):220227.

Objectives The sensitizing properties of organic acid anhydrides (OAA) were evaluated in a rat model.

Methods The development of specific immunoglobulin (Ig) $\mathrm{E}$ and $\mathrm{Ig} \mathrm{G}$ in serum was investigated after immunization with $14 \mathrm{OAA}$ and $3 \mathrm{OAA}$ conjugates. Brown Norway rats were injected intradermally with $0.1 \mathrm{ml}$ of $0.2 \mathrm{M} \mathrm{OAA}$ in liquid paraffin or $1.4 \mathrm{mg}$ of rat serum albumin conjugate in saline. Serum samples were collected after 4 weeks. Antibodies were analyzed with enzyme-linked immunosorbent assay.

Results The serum titers of specific Ig E after immunization with the different free OAA varied from $<50$ to 6400 . The rats immunized with 4-methylphthalic anhydride exhibited the highest titers. The specificity of Ig $\mathrm{E}$ was demonstrated by enzyme-linked immunosorbent assay inhibition tests. A good correlation was observed between the Ig $\mathrm{E}$ and Ig G titers. Immunization with OAA conjugates showed results parallel to the findings for the free compounds. Importantly, the Ig $\mathrm{E}$ titers for the OAA agreed well with findings from guinea pigs and with literature data from epidemiologic studies of exposed workers.

Conclusions The present animal model may be a valuable tool for predicting the sensitizing potential of OAA and possibly the sensitizing potential of low-molecular-weight compounds in general. Furthermore, the antibody specificity of the haptens and the variations in the magnitude of the antibody titers indicate a valuable approach for studies of quantitative structure-activity relationships.
\end{abstract}

Key terms animal model, immunoglobulin E, immunoglobulin G, occupational allergy, structure-activity relationship.

Knowledge about the chemical determinants of inhalant allergens that cause immune responses has both theoretical and practical significance. Thus interest in predictive testing of allergenicity $(1,2)$ and in quantitative structureactivity relationships $(3-6)$ is growing.

There are several approaches for testing allergenicity in chemicals. Wass \& Belin (7) suggested that the in-vitro reactivity of chemicals with proteins can be used to predict their sensitizing properties. Sarlo \& Clark (8) introduced a stepwise procedure to detect chemical allergens, including both subcutaneous and inhalation sensitization of guinea pigs. The alternative use of a rat bioassay was described by Pauluhn (6). Topical sensitization of mice followed by the registration of alterations of the serum concentration of immunoglobulin (Ig) $\mathrm{E}$ and differential cytokine production is another interesting approach $(5,9$, 10). The induction of specific antibodies may be a sensitive indicator of respiratory sensitization (1).
Knowledge of structure-activity relationships for respiratory sensitizers may be an important tool in predicting the immunogenicity of chemicals (3). Thus a need exists for animal experimental data on relevant chemicals to be combined with chemical, physical, and epidemiologic information.

Organic acid anhydrides (OAA) are reactive chemicals that induce specific Ig $\mathrm{E}$ antibodies in exposed workers $(11-14)$. $\operatorname{Ig} \mathrm{E}$ is involved in the pathogenesis behind rhinoconjunctivitis and asthma in association with exposure to OAA. Thus OAA are good model compounds for studies of the relationship between chemical characteristics and the induction of specific antibodies. Guinea pigs intradermally immunized with 13 OAA showed a wide variation of induced $\operatorname{Ig} G_{1}$ titers between the different $O A A$ (15). However, while $\mathrm{Ig} \mathrm{G}_{1}$ is the main anaphylactic antibody in guinea pigs, $\mathrm{Ig} \mathrm{E}$ is important for the immediate allergic responses in rats, as well as in humans $(16,17)$.

1 Department of Occupational and Environmental Medicine, University Hospital, Lund, Sweden.

Reprint requests to: Dr Hans Welinder, Department of Occupational and Environmental Medicine, University Hospital, S22185 Lund, Sweden. [e-mail: hans.welinder@ymed.lu.se] 
The aim of the present study was to evaluate antibody responses in rats after intradermal immunization with OAA as a model of predictive testing for allergenicity.

\section{Material and methods}

\section{Animals}

Male, inbred Brown Norway (BN) rats (Møllegaard Breeding Center Ltd, Denmark) were used. The strain origin was Zentralinstitut für Versuchstierzucht, Hannover, Germany. They weighed 100 to $150 \mathrm{~g}$ when obtained. The rats were acclimatized to the animal facilities for 1 week before the experiments. The microbiological monitoring of the animals and the animal facilities complied with the recommendations of the European Laboratory Animal Science Associations.

\section{Ethics}

The animal experiments were approved by the Animal Research Ethics Committee of the Lund University.

\section{Chemicals}

Succinic anhydride (SA), 4-methylhexahydrophthalic anhydride (4-MHHPA; cis- isomer with regard to the carboxyl groups and a mixture of cis- and trans-isomers with regard to the methyl group), and 1,2,3,6-tetrahydrophtha1ic anhydride (1,2,3,6-THPA) were obtained from Janssen Chimica (Geel, Belgium); meso-dimethylsuccinic anhydride (DMSA) was prepared from meso-dimethylsuccinic acid (Aldrich, Gillingham, United Kingdom) in our laboratory (identity and purity checked with gas chromatography with mass-spectrometric detection (GC-MS) and nuclear magnetic resonance; meso-diethylsuccinic anhydride (DESA) was obtained from Synthelec AB (Lund, Sweden); maleic anhydride (MA) and cis-hexahydrophthalic anhydride (cis-HHPA) came from Merck (Darmstadt, Germany); methylmaleic anhydride (MMA) and 3,4,5,6-tetrahydrophthalic anhydride (3,4,5,6-THPA) were from Sigma Chemical Co (St Louis, MO, USA); 4methylphthalic anhydride (4-MPA) came from AldrichChemie (Steiheim, Germany); 3,4-methyltetrahydrophthalic anhydride (3,4-MTHPA) and 4,4-methyltetrahydrophthalic anhydride (4,4-MTHPA) were prepared in our laboratory with identity and purity checked with GC-MS; phthalic anhydride (PA) was obtained from Mallinckrodt Inc (Paris, KY, USA); and trimellitic anhydride (TMA) came from Fluka Chemie AG (Buchs, Switzerland). The chemical structures of the OAA are shown in figure 1. The purity of the various OAA was $>97 \%$. However, DESA was found to isomerize during storage to the corresponding raceme form, which reduced the purity. Rat serum albumin (RSA, fraction V) was purchased from the Sigma Chemical Company (St Louis, MO, USA), and liquid paraffin was obtained from Apoteksbolaget (Umeå, Sweden).

\section{Preparation of conjugates between anhydrides and rat serum albumin}

The conjugates were prepared by reacting the anhydrides with RSA. All the anhydrides were dissolved in water-free dioxane and dripped into a cooled $\left(+4\right.$ to $\left.+8^{\circ} \mathrm{C}\right)$ and stirred solution containing $3 \mathrm{mg}$ of RSA per milliliter of $0.1 \mathrm{M}$ sodium hydrogen carbonate $\left(\mathrm{NaHCO}_{3}\right)$. The molar ratio between the added anhydride and RSA was 60:1. The mixtures were stirred for 18 hours. The anhydride-RSA conjugates were purified from low-molecularweight compounds ( $<30000 \mathrm{Da}$ ), and the $0.1 \mathrm{M} \mathrm{NaHCO}_{3}$ buffer was substituted by $0.1 \mathrm{M}$ ammonium hydrogen carbonate $\left(\mathrm{NH}_{4} \mathrm{HCO}_{3}\right)$ via ultrafiltration processing

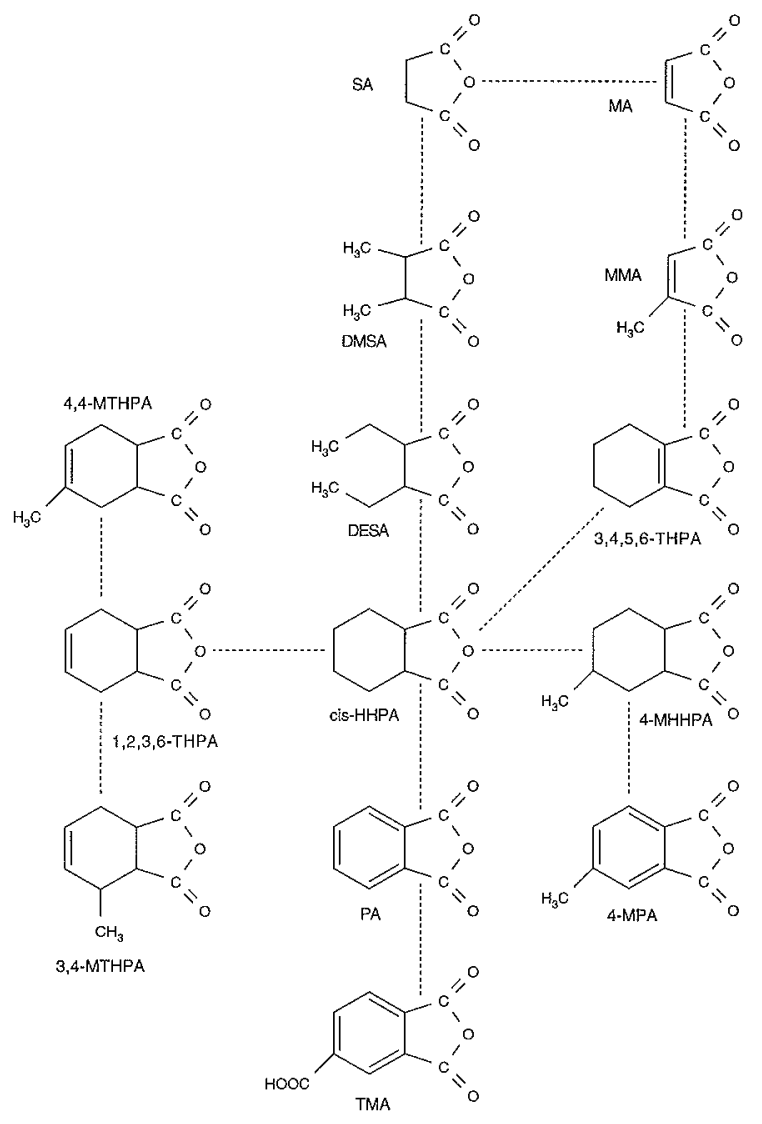

Figure 1. Chemical structures of the organic acid anhydrides used in the experiments. $(S A=$ succinic anhydride, $D M S A=$ dimethylsuccinic anhydride, $D E S A=$ diethylsuccinic anhydride, $M A=$ maleic anhydride, $M M A=$ methylmaleic anhydride, cis-HHPA = cis-hexahydrophthalic anhydride, 4-MHHPA = 4-methylhexahydrophthalic anhydride, $\mathrm{PA}=$ phthalic anhydride, 4-MPA $=4$-methylphthalic anhydride, TMA = trimellitic anhydride, 3,4,5,6-THPA =3,4,5,6-tetrahydrophthalic anhydride, 1,2,3,6-THPA $=1,2,3,6$-tetrahydrophthalic anhydride, 3,4-MTHPA = 3,4-methyltetrahydrophthalic anhydride), 4,4-MTHPA $=4,4$-methyltetrahydrophthalic anhydride) 
(Amicon Co, Denver, MA, USA) and stored at $-20^{\circ} \mathrm{C}$ after lyophilization.

Determination of hapten density. The hapten density (HD) was determined for the conjugates by different methods. The "UV method" was a spectrophotometric one, according to Zeiss et al (11). In the "HCl method" the conjugates were hydrolyzed at 3 selected concentrations of hydrogen chloride $(\mathrm{HCl})(0.1,1$, or $6 \mathrm{M})$, respectively. The samples were evaporated and then worked-up and analyzed by GC-MS according to Lindh \& Jönsson (18). The hydrolysis conditions giving the highest yield were chosen for the determinations. The "TNBS method" was based on the titration of free amino groups by 2,4,6-trinitrobenzene sulfonic acid (TNBS), according to Snyder \& Sobocinski (19).

\section{Immunization}

Free anhydride. Unconjugated, free anhydrides were dissolved in dioxane; then liquid paraffin was added to make a $0.2 \mathrm{M}$ solution (the final concentration of dioxane was $3 \%$ ). The rats were immunized via intradermal injection with $0.1 \mathrm{ml}$ (in 2 portions of $0.05 \mathrm{ml}$ ) of the freshly prepared solutions. Each anhydride was injected into 7 animals. As a control, 7 rats were intradermally injected with liquid paraffin; the dose was $0.1 \mathrm{ml}$. Serum samples were collected 28 days after the immunization.

Conjugate. The procedures for the conjugates were the same for the free anhydrides, but with anhydrides conjugated to RSA. The dose was $1.4 \mathrm{mg}$ of SA-RSA, or cisHHPA-RSA, or MA-RSA, respectively, in $0.14 \mathrm{ml}$ of 0.15 $\mathrm{M}$ sodium chloride $(\mathrm{NaCl})$. Seven rats were intradermally injected with RSA as a control group, the dose was 1.4 mg.

\section{Antibody determinations by enzyme-linked immunosorbent assay}

Specific immunoglobulin $E$. The following steps were used for specific Ig E: (i) polystyrene microtiter plates (Nunc-Immuno Plate, Nunc, Kamstrup, Denmark) were coated by adding $100 \mu \mathrm{l} /$ well with $0.015 \%$ (in phosphatebuffered saline) anhydride-RSA conjugate; (ii) uncoated protein-binding sites were blocked by adding $200 \mu \mathrm{l} /$ well with $4 \%$ bovine serum albumin and the plates were stored with blocking solution at $-18^{\circ} \mathrm{C}$ until use; (iii) sera taken from immunized $\mathrm{BN}$ rats were added to the plates at 100 $\mu 1 /$ well in 2-fold dilutions, starting from 1:50, and incubated for 1 hour at room temperature; (iv) sheep anti-rat Ig E (ICN ImmunoBiologicals Inc, Costa Mesa, CA, USA) of dilution 1:3000 was added at $100 \mu 1 /$ well and incubated for 1 hour at room temperature; (v) alkaline phosphatase-conjugated rabbit anti-sheep Ig G (Fc Fragment; ICN Biomedicals) of dilution 1:5000 was added at $100 \mu \mathrm{l} /$ well and incubated for 1 hour at room temperature [the plates were washed after each addition with a Titertek Microplate Washer (Flow Laboratories, Rickmansworth, United Kingdom)]; and (vi) substrate (p-nitrophenyl phosphate, Sigma Chemical Co) of $0.1 \%$ in diethanolamine buffer was added at $100 \mu \mathrm{l} /$ well. After 2 hours at room temperature, the wells were read at $405 \mathrm{~nm}$ by a filter photometer (Titertek Multiskan, Eflab Oy, Helsinki, Finland). All the samples were analyzed in triplicate, with RSA-coated wells as controls for nonspecific binding. The result of each sample was expressed as the value of optical density (OD). The titer was the highest dilution at which the corresponding OD value was greater than the mean OD value of control rat sera plus 3 standard deviations. If the "mean OD + 3SD" was less than 0.05 , the latter value was taken as the limit.

Cross-inhibition tests. Antisera of the rats immunized with 4-MHHPA were pooled and diluted at 1:50 in phosphate-buffered saline. Various anhydride-RSA or anhydrides conjugated to guinea pig serum albumin (GPSA) were added to the sera at concentrations of $0,0.0064$, $0.032,0.16,0.8$ and $4 \mathrm{mg} / \mathrm{ml}$, and after incubation at $4^{\circ} \mathrm{C}$ for 20 hours, specific Ig $\mathrm{E}$ against 4-MHHPA-RSA was analyzed.

Specific immunoglobulin $G$. The analysis for Ig $G$ was performed according to the method for specific Ig E, but alkaline phosphatase-conjugated goat anti-rat Ig G (working dilution 1:4000; H + L, Zymed Laboratories, Inc, San Francisco, CA, USA) was added directly in the fourth step.

\section{Statistics}

For comparisons of the distributions between different groups, the Mann-Whitney U-test was used. The Spearman rank correlation (rs) method was applied to investigate the correlation between 2 variables which can be expressed in a rank order. Statistical significance refers to $\mathrm{P} \leq 0.05$ (2-tailed).

\section{Results}

The hapten density for all the conjugates $(\mathrm{N}=14)$ was analyzed by the TNBS method. It varied between 16 and 27 $\mathrm{mol} / \mathrm{mol}$ for the different conjugates (table 1). For 6 of the conjugates, the molar absorbances were large enough to permit determinations also by the UV method. Four of these conjugates corresponded well with the results from the TNBS method, while MA-RSA and TMA-RSA showed a higher and lower hapten density, respectively. The hapten densities after the acidic hydrolysis were lower than those determined by the other 2 methods.

The titers of specific Ig $\mathrm{E}$ after the immunization of the rats with the free anhydrides varied from negative to 6400 (table 2). SA and 3,4,5,6-THPA did not give 
positive results. Titers (median) below 1000 were obtained with DMSA, DESA, MA, MMA, 1,2,3,6-THPA, 3,4MTHPA and 4,4-MTHPA, while titers above 1000 were obtained with cis-HHPA, 4-MHHPA, PA, 4-MPA, and TMA. The rats immunized with 4-MPA exhibited the highest titers, which were significantly different from the titers of all the other OAA. 4-MPA and DMSA also demonstrated significant differences in titers compared with their nonmethylated analogues PA and SA, respectively.

In the ELISA (enzyme-linked immunosorbent assay) inhibition tests with anti-4-MHHPA sera, the strongest inhibition was shown by 4-MHHPA-RSA at each concentration of the conjugate. For this anhydride a $50 \%$ inhibition occurred at a conjugate concentration of $<0.0064$ $\mathrm{mg} / \mathrm{ml}$ in the antisera, and the inhibition was $>95 \%$ when the conjugate concentration in the antisera was $0.16 \mathrm{mg} /$ ml. In addition 4,4-MTHPA-RSA, 4-MHHPA-GPSA, and cis-HHPA-RSA showed inhibitions of $>90 \%$ at the highest concentration $(4 \mathrm{mg} / \mathrm{ml})$ employed. For the same anhydride (4-MHHPA, cis-HHPA, 4-MPA), the inhibition of the RSA conjugate was larger than that of the corresponding GPSA conjugate (figure 2).

The titers of specific Ig G varied from 200 to 6400 (table 2). As for Ig E, 4-MPA exhibited the highest titers (P $\leq 0.05$ ), and SA and 3,4,5,6-THPA had the lowest titers. There was a close correlation between the $\mathrm{Ig} \mathrm{E}$ and $\mathrm{Ig}$ $\mathrm{G}$ titers for the various OAA ( $\mathrm{rs}=0.92, \mathrm{P}=0.0001$ ).

The tested conjugates also induced the formation of positive specific Ig E and Ig G. The titers of Ig E varied from 50 to 800 , and those for specific Ig G varied from 200 to 1600 (table 3). cis-HHPA-RSA induced higher titers than either SA-RSA or MA-RSA.

The lack of correlation ( $\mathrm{rs}=0.3, \mathrm{P}=0.5$ ) between the $\mathrm{Ig}$ E titers and the reactivity of the anhydrides demonstrated by their hydrolysis rate constants according to Eberson \& Landström (20) is shown in figure 3.

Table 1. Hapten densities of the conjugates between different organic acid anhydrides and rat serum albumin at the molar ratio of $60: 1$ as determined by a spectrophotometric method (UV method), the analysis of the corresponding acids after acidic [hydrogen chloride ( $\mathrm{HCl}$ ) hydrolysis of the conjugates] $(\mathrm{HCl}$ method), and indirect analysis by the determination of free amino groups by 2,4,6-trinitrobenzene sulfonic acid (TNBS method). (NA = not analyzed)

\begin{tabular}{|c|c|c|c|c|}
\hline \multirow[t]{2}{*}{ Conjugate } & \multicolumn{4}{|c|}{ Hapten density (mol/mol) } \\
\hline & $\begin{array}{l}\text { UV } \\
\text { method }\end{array}$ & $\begin{array}{c}\mathrm{HCl} \\
\text { method }\end{array}$ & $\mathrm{HCl}$ & $\begin{array}{l}\text { TNBS } \\
\text { method }\end{array}$ \\
\hline SA-RSA (succinic anhydride-rat serum albumin) & NA & 11 & 6 & 23 \\
\hline DMSA-RSA (dimethylsuccinic anhydride-rat serum albumin) & NA & 7 & 6 & 22 \\
\hline DESA-RSA (diethylsuccinic anhydride-rat serum albumin) & NA & NA & & 23 \\
\hline MA-RSA (maleic anhydride-rat serum albumin) & 48 & 11 & $0 . \ddot{1}$ & 23 \\
\hline MMA-RSA (methylmaleic anhydride-rat serum albumin) & 28 & 7 & 0.1 & 22 \\
\hline cis-HHPA-RSA (cis-hexahydrophthalic anhydride-rat serum albumin) & NA & 10 & 0.1 & 20 \\
\hline 4-MHHPA-RSA (4-methy/hexahydrophthalic anhydride-rat serum albumin) & NA & 13 & 0.1 & 22 \\
\hline 1,2,3,6-THPA-RSA (1,2,3,6-tetrahydrophthalic anhydride-rat serum albumin) & NA & 11 & 0.1 & 24 \\
\hline 3,4,5,6-THPA-RSA ((3,4,5,6-tetrahydrophthalic anhydride-rat serum albumin) & 21 & 10 & 0.1 & 24 \\
\hline 3,4-MTHPA-RSA (3,4-methy/tetrahydrophthalic anhydride-rat serum albumin) & NA & NA &. & 16 \\
\hline 4,4-MTHPA-RSA (4,4-methy/tetrahydrophthalic anhydride-rat serum albumin) & NA & NA & 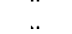 & 25 \\
\hline PA-RSA (phthalic anhydride-rat serum albumin) & 26 & 19 & 6 & 27 \\
\hline 4-MPA-RSA (4-methylphthalic anhydride-rat serum albumin) & 26 & NA & .. & 27 \\
\hline TMA-RSA (trimellitic anhydride-rat serum albumin) & 13 & NA &. & 22 \\
\hline
\end{tabular}

Table 2. Titers of specific immunoglobulin $(\mathrm{lg}) \mathrm{E}$ and $\mathrm{G}$ by enzyme-linked immunosorbent assay of sera from rats $(\mathrm{N}=7)$ after intradermal immunization respectively with $0.1 \mathrm{ml}$ of $0.2 \mathrm{M}$ solutions of different organic acid anhydrides in liquid paraffin.

\begin{tabular}{|c|c|c|c|c|}
\hline \multirow[t]{2}{*}{ Anhydride } & \multicolumn{2}{|c|}{ IgE titer } & \multicolumn{2}{|c|}{$\lg \mathrm{G}$ titer } \\
\hline & Median & Range & Median & Range \\
\hline SA (succinic anhydride) & $<50$ & $<50$ & $<50$ & $<50$ \\
\hline DMSA (dimethylsuccinic anhydride) & 200 & $100-400$ & 800 & $400-1600$ \\
\hline DESA (diethylsuccinic anhydride) & 800 & $400-800$ & 1600 & $800-1600$ \\
\hline MA (maleic anhydride) & 800 & $800-3200$ & 1600 & $1600-3200$ \\
\hline MMA (methylmaleic anhydride) & 200 & $100-200$ & 400 & $200-800$ \\
\hline cis-HHPA (cis-hexahydrophthalic anhydride) & 1600 & $1600-3200$ & 3200 & $1600-3200$ \\
\hline 4-MHHPA (4-methylhexahydrophthalic anhydride) & 1600 & $800-1600$ & 3200 & $1600-3200$ \\
\hline 1,2,3,6-THPA (1,2,3,6-tetrahydrophthalic anhydride) & 800 & $200-1600$ & 800 & $200-1600$ \\
\hline $3,4,5,6$-THPA $(3,4,5,6$-tetrahydrophthalic anhydride $)$ & $<50$ & $<50-50$ & $<50$ & $<50-50$ \\
\hline 3,4-MTHPA (3,4-methyltetrahydrophthalic anhydride) & 800 & $400-800$ & 1600 & $800-1600$ \\
\hline 4,4-MTHPA (4,4-methyltetrahydrophthalic anhydride) & 800 & $800-3200$ & 1600 & $800-3200$ \\
\hline PA (phthalic anhydride) & 3200 & $1600-3200$ & 3200 & $1600-3200$ \\
\hline 4-MPA (4-methylphthalic anhydride) & 3200 & $3200-6400$ & 6400 & $3200-6400$ \\
\hline TMA (trimellitic anhydride) & 1600 & $800-6400$ & 1600 & $800-3200$ \\
\hline
\end{tabular}




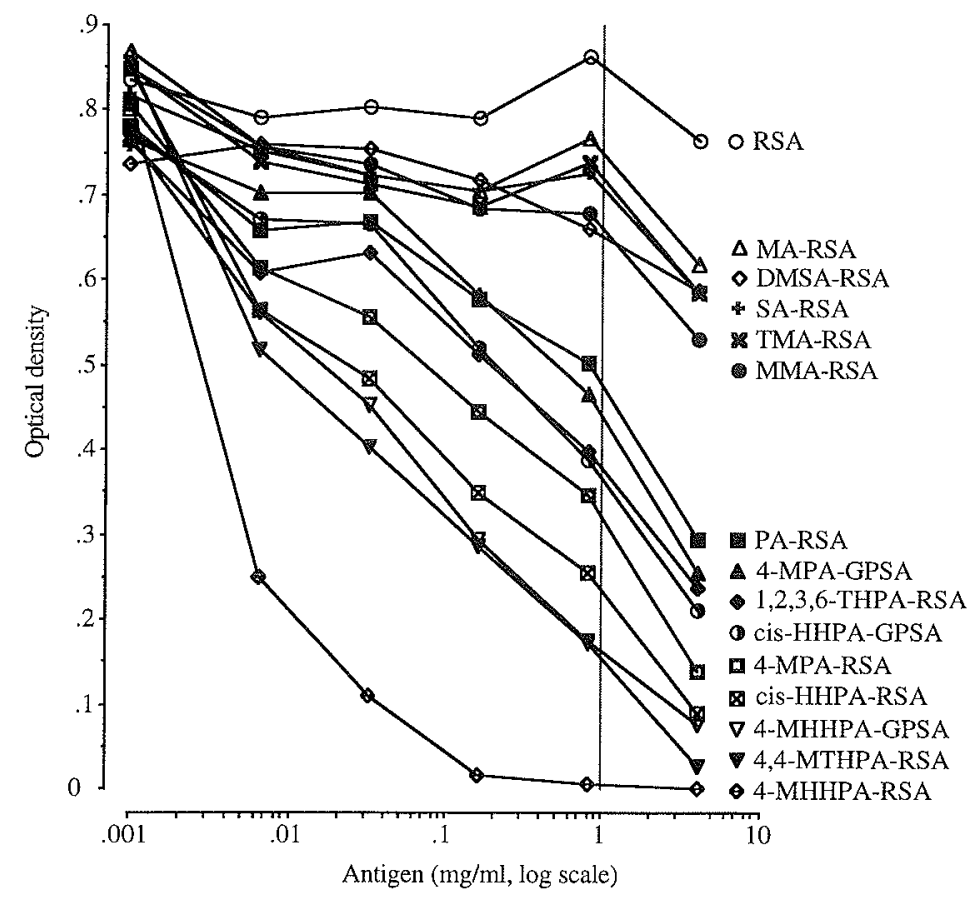

Figure 2. The enzyme-linked immunosorbent assay inhibition test. Pooled sera from the rats immunized with 4-methylhexahydrophthalic anhydride were incubated with the conjugates between different organic acid anhydrides (OAA) and rat serum albumin (RSA) or guinea pig serum albumin (GPSA) at concentrations of $4,0.8,0.16,0.032$, and $0.0064 \mathrm{mg} / \mathrm{ml}$ at $4^{\circ} \mathrm{C}$ for 20 hours; thereafter immunoglobulin $E$ was analyzed from 4-MHHPA-RSA coated plates. The anhydride conjugates are listed from top to bottom in increasing order according to their inhibition. ( $S A=$ succinic anhydride, DMSA = dimethylsuccinic anhydride, $M A=$ maleic anhydride, $M M A=$ methylmaleic anhydride, cis-HHPA = cis-hexahydrophthalic anhydride, 4-MHHPA = 4-methylhexahydrophthalic anhydride, $\mathrm{PA}=$ phthalic anhydride, 4-MPA $=4$-methyl phthalic anhydride, TMA $=$ trimellitic anhydride 1,2,3,6-THPA = 1,2,3,6-tetrahydrophthalic anhydride, 4,4-MTHPA $=4,4$-methyltetrahydrophthalic anhydride)

Table 3. Titers of specific immunoglobulin ( $\mathrm{lg}) \mathrm{E}$ and $\mathrm{G}$ by enzyme-linked immunosorbent assay of sera from 3 groups of the rats $(\mathrm{N}=7)$ after intradermal immunization with $1.4 \mathrm{mg}$ of different conjugates between organic acid anhydrides and rat serum albumin in saline.

\begin{tabular}{|c|c|c|c|c|}
\hline \multirow[t]{2}{*}{ Antigen } & \multicolumn{2}{|c|}{ IgEtiter } & \multicolumn{2}{|c|}{ IgG titer } \\
\hline & Median & Range & Median & Range \\
\hline SA-RSA (succinic anhydride-rat serum albumin) & 200 & $50-800$ & 400 & $200-1600$ \\
\hline MA-RSA (maleic anhydride-rat serum albumin) & 200 & $100-400$ & 400 & $200-1600$ \\
\hline cis-HHPA-RSA (cis-hexahydrophthalic anhydride-rat serum albumin) & 800 & $400-800$ & 800 & $800-1600$ \\
\hline
\end{tabular}

\section{Discussion}

Positive specific Ig E and Ig G titers were obtained after intradermal immunization of rats with various free OAA. However, the magnitude of the induced titers varied. SA and 3,4,5,6-THPA failed to give detectable antibody production, while the highest specific Ig E titers were shown by cis-HHPA, 4-MHHPA, TMA, and especially PA and 4-MPA. A close correlation was exhibited between the Ig $\mathrm{E}$ and Ig $\mathrm{G}$ titers. Immunization with the corresponding RSA conjugates showed positive titers for $\mathrm{SA}, \mathrm{MA}$, and cis-HHPA.

Equimolar amounts of the anhydrides were used for the immunizations. It is of course possible that the effective amounts differed because of the different levels of stability of the anhydrides before injection. However, in guinea pigs, similar titers were obtained after immunization with $0.3 \mathrm{M}$ suspensions and $0.2 \mathrm{M}$ solutions, respectively (Zhang et al, unpublished observations). Thus the exact amount of anhydride does not seem to be critical at the administered dose of immunization. A 10-fold decrease in concentration for very reactive OAA before immunization may have a substantial effect. However, very high titers were observed for the reactive MA in guinea pigs (15).

The antibody titers analyzed by ELISA may be dependent on the quality of the hapten conjugate used for the determinations. If the conjugates have a different hapten density, they may show different responses in the assays (21). However, there are indications that hapten densities in the range of $10-25 \mathrm{~mol} / \mathrm{mol}$ are optimal and show a low variation in activity $(21,22)$. The conjugates in the present study had hapten densities of $16-27 \mathrm{~mol} /$ mol, as demonstrated by the TNBS method. These results were confirmed by the UV method. Lower values were obtained by the $\mathrm{HCl}$ method. However, the haptan densities analyzed by the $\mathrm{HCl}$ method also fell in the range of $10-25$, except for DMSA-RSA and MMA-RSA, both of which had a hapten density of 7. On the other hand, hapten densities as low as 6 have been shown to exhibit only minor reductions in antibody titers (22). Thus we believe that the conjugates in our work were within their optimal hapten density range.

To identify and produce the optimal conjugates for a large number of haptens is expensive and time-consuming. Thus it has been suggested that the total $\mathrm{Ig} \mathrm{E}$ induced 
by immunization may be used as an alternative indicator of the immunogenicity of a chemical (5). However, this possibility has to be tested further.

Ig $\mathrm{E}$ and Ig $\mathrm{G}$ are 2 different classes of anaphylactic antibodies in rats, both of which increase after active sensitization $(23,24)$. There was a close correlation between the Ig E and Ig G titers in this study. Both antibody classes showed similar patterns and levels of titers.

SA showed negative results, while a positive titer of Ig $\mathrm{E}$ was induced by $\mathrm{MA}$. The present negative findings for SA, as compared with MA, can be explained by the flexibility of the succinic acid molecule and the fact that $\mathrm{SA}$ is an endogenous compound. In addition, MA may react by the double bond with thiol groups in proteins. However, the immunogenicity of MA is interesting, in light of the small size of the molecule. The antibody titers increased when SA was substituted with methyl groups (DMSA), and even more so when the substituents were ethyl groups (DESA). The titers increased still more when DESA was ring closed to the more rigid cis-HHPA. Further methylation to 4-MHHPA caused no additional increase in the titers. However, even higher titers were observed after immunization with the corresponding aromatic anhydrides PA and 4-MPA. When the methyl group in 4-MPA was replaced by a carboxyl group (TMA), the titers significantly decreased. Thus the chemical character of the substituent is important. The results of PA and TMA agree with the observed serum Ig E levels in mice after topical application of the free anhydrides (9). Substitution of MA by MMA and 3,4,5,6-THPA showed a different pattern of induced antibodies as compared with the effect caused by the corresponding structural changes of SA. A possible explanation may be the instability of the MMA and 3,4,5,6-THPA conjugates under in-vivo conditions (25). The isomerization of the double-bond position in 3,4,5,6-THPA to the 1,2,3,6-THPA isomer showed a significant positive effect on the $\operatorname{Ig} \mathrm{E}$ titers. A corresponding effect is seen when the position of the methyl group in MTHPA is shifted from the 3- to the 4-position on the 6-carbon ring.

The specificity of the antibody readings was demonstrated by the low readings of the RSA controls on the ELISA microtiter plates, as well as the low readings for the control animals immunized with RSA. The specificity of the antibodies was further demonstrated by the ELISA inhibition tests of specific Ig E to 4-MHHPA. 4-MHHPARSA presented the highest inhibition. Other OAA showed different inhibitions, depending on their structural similarities with 4-MHHPA, as was demonstrated in an earlier work (26). Thus cis-HHPA-RSA and 4,4-MTHPA-RSA showed inhibitions close to that of 4-MHHPA-RSA. Corresponding inhibitory potentials were obtained for the different RSA and GPSA conjugates. For the same anhydrides, the RSA-conjugates exhibited higher inhibitions than those of the corresponding GPSA conjugates.

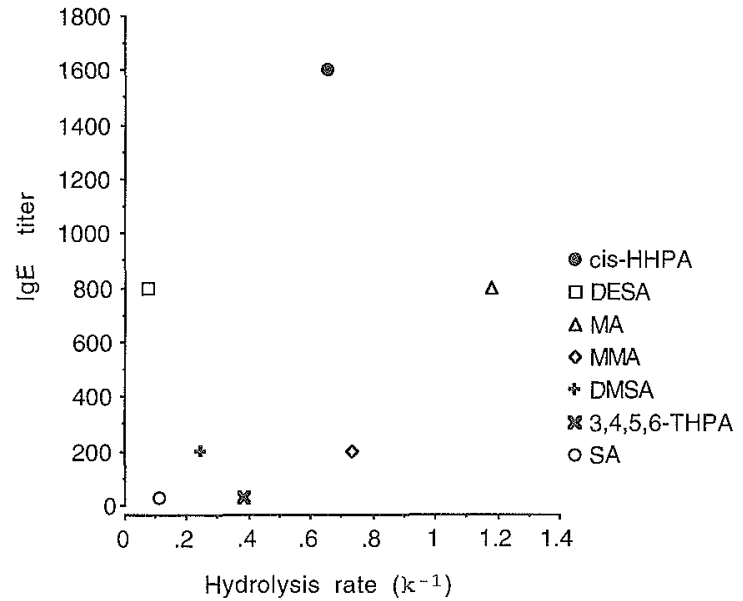

Figure 3. Correlation ( $r s=0.3, P=0.5$ ) between induced $\lg E$ titers and the hydrolysis rate constants of succinic anhydride (SA), dimethylsuccinic anhydride (DMSA), diethylsuccinic anhydride (DESA), cis-hexahydrophthalic anhydride (cis-HHPA), maleic anhydride (MA), methylmaleic anhydride (MMA), and 3,4,5,6-tetrahydrophthalic anhydride (3,4,5,6-THPA) according to Eberson \& Landström (20).

However, the differences were limited and therefore demonstrated a high hapten specificity of the antibodies.

OAA induce antibody formation by conjugation in vivo; the conjugates are recognized as "nonself" proteins by the immune system. Thus antibody formation after immunization may be influenced by the chemical reactivity of the anhydrides (7). However, no correlation was seen between the hydrolysis rate constants and the antibody titers in the present work, as was observed in a previous study of guinea pigs (15). Thus there is no simple correlation between chemical reactivity and sensitizing potential. The chemical reactivity of a low-molecularweight allergen is only one of several parameters which may affect sensitization.

Whereas the results of immunization with the free anhydrides may reflect several other characteristics of the anhydrides, including solubility and reactivity, immunization with the corresponding serum-albumin conjugates mainly reflects the "nonself" recognition of the conjugate. Thus immunization with free anhydrides and corresponding protein conjugates, respectively, may give different information on the sensitizing potential of the anhydrides. Imunization with cis-HHPA-RSA, MA-RSA, and SA-RSA showed positive antibody formation. If a hapten density of about $25 \mathrm{~mol} / \mathrm{mol}$ is assumed, the amount of free anhydride bound to the protein carrier used for immunization is about $1 / 30$ of the doses of free anhydrides used for immunization. Thus immunization with the conjugate appears to be more efficient than with free anhydride. This difference may simply reflect the amount of free anhydride which reacts with proteins after injection. Interestingly, free SA did not induce detectable antibody levels, but SA-RSA did. A low sensitizing potential of SA has also been demonstrated by the lack of response to 
bronchial challenge in SA-sensitized guinea pigs (Zhang et al, unpublished data). Rats immunized with SA or MA bound to the RSA carrier induced similar titers but differed markedly after immunization with the unconjugated ones. This finding may indicate an effect of both chemicophysical characteristics and the epitopic structures on the sensitizing potential.

A correlation $(\mathrm{rs}=0.63, \mathrm{P}<0.05)$ can be seen between the rat $\operatorname{Ig} E$ titers in the present study and the $\operatorname{Ig} G_{1}$ titers after the immunization of guinea pigs with the same anhydrides in a previous study (15) (table 4). Passive cutaneous anaphylaxis tests of specific guinea pig Ig E suggested an enhanced effect on Ig E by methyl group substitution. However, in the present study, methyl group substitution in PA and SA resulted in increased titers, while in cis-HHPA no effect was found and in MA there was a decreasing effect. Thus there may be an animal species difference.

A close correlation was observed between specific Ig $\mathrm{G}_{1}$ titers and lung resistance in guinea pigs sensitized with cis-HHPA (27). The relationship between specific Ig E and the airway response in rats was not evaluated by us in this study. However, a relationship between an increased dose of antigen, an increased Ig E titer, and enhanced airway resistance has been demonstrated earlier (28).

There are indications that chemical allergens that cause respiratory tract sensitization in humans also induce sensitization in experimental animals after intradermal or topical immunization (5). However, there is no conclusive evidence that animal models can predict the sensitizing potential of chemicals in humans $(1,29)$. There is a reasonable agreement between the results from the present rat model and epidemiologic studies of exposed workers. Hence studies on exposed workers have shown a high prevalence of positive specific Ig E in workers exposed to MTHPA (14), TMA (30), cis-HHPA, and 4-MHHPA (31), while PA has shown lower Ig E levels (13). There are, to our knowledge, no reports of specific Ig $\mathrm{E}$ in

Table 4. Rat serum immunoglobulin (Ig) E titers (median, $N=7$ ) and guinea pig serum $\operatorname{lgG}_{1}$ titers (median) [Welinder et al (15)] analyzed by enzyme-linked immunosorbent assay after intradermal immunization with free organic acid anhydrides.

\begin{tabular}{lrr}
\hline Antigen & $\begin{array}{c}\text { Rat lgE titer } \\
\text { (median) }\end{array}$ & $\begin{array}{r}\text { Guinea pig } \\
\text { lgG } \text { titer }_{1} \\
\text { (median) }\end{array}$ \\
\hline SA (succinic anhydride) & $<50$ & 300 \\
MA (maleic anhydride) & 800 & 51200 \\
MMA (methylmaleic anhydride) & 200 & 6400 \\
cis-HHPA (cis-hexahydrophthalic anhydride) & 1600 & 12800 \\
4-MHHPA (4-methylhexahydrophthalic anhydride) & 1600 & 12800 \\
1,2,3,6-THPA (1,2,3,6-tetrahydrophthalic anhydride) & 800 & 6400 \\
3,4,5,6-THPA (3,4,5,6-tetrahydrophthalic anhydride) & $<50$ & 800 \\
4,4-MTHPA (4,4-methyltetrahydrophthalic anhydride) & 800 & 102400 \\
3,4-MTHPA (3,4-methyltetrahydrophthalic anhydride) & 800 & 25600 \\
PA (phthalic anhydride) & 3200 & 51200 \\
4-MPA (4-methylphthalic anhydride) & 3200 & 51200 \\
TMA (trimellitic anhydride) & 1600 & 12800 \\
\hline
\end{tabular}

humans to SA, DMSA, DESA, MA, MMA, 1,2,3,6THPA, 3,4,5,6-THPA, and 4-MPA. However, this lack of evidence may be due to a lack of investigations on these chemicals or due to the fact that they have little use in industry.

In conclusion, the magnitude of the specific Ig E titers in rats after intradermal immunization showed interesting relationships with the chemical structures of the various OAA. Importantly, the results agreed well with those from a corresponding study of $\operatorname{Ig~}_{1}$ in guinea pigs, and with findings from exposed workers. Thus the present model may be a valuable tool for predicting the sensitizing potential of low-molecular-weight compounds. Furthermore, the antibody specificity to the haptens demonstrated by the inhibition tests and the variation in antibody titers after immunization make the OAA an interesting model for studies on quantitative structure-activity relationships.

\section{Acknowledgments}

The project was supported by grants from the European Union, the Swedish Council for Work Life Research, The Vårdal Foundation, the Swedish Medical Research Council, and the Medical Faculty, Lund University.

We thank Ms Birgitta Björk for her skillful technical assistance, Mr Christian Lindh, MSc, for his preparation of the 3,4- and 4,4-MTHPA isomers, and the Department of Microbiology, Lund University, for the use of their animal facilities.

\section{References}

1. Briatico-Vangosa G, Braun CLJ, Cookman G, Hofman T, Kimber I, Loveless SE, et al. Respiratory allergy: hazard identification and risk assessment. Fundam Appl Toxicol 1994:23:145-58.

2. Karol MH. Animal models of occupational asthma. Eur Respir J 1994;7:555-68.

3. Agius RM, Nee J, McGovern B, Roberson A. Structureactivity hypothesis in occupational asthma caused by low molecular weight substances. Ann Occup Hyg 1991;35:129-37.

4. Karol MH, Graham C, Gealy R, Macina OT, Sussman N, Rosenkranz HS. Structure-activity relationships and computer-assisted analysis of respiratory sensitization potential. Toxicol Lett 1996;86:187-91.

5. Kimber I, Hilton J, Basketter D, Dearman RJ. Predictive testing for respiratory sensitization in the mouse. Toxicol Lett 1996;86:193-8.

6. Pauluhn J. Predictive testing for respiratory sensitization. Toxicol Lett 1996;86:177-85.

7. Wass U, Belin L. An in vitro method for predicting sensitizing properties of inhaled chemicals. Scand J Work Environ Health 1990;16:208-14. 
8. Sarlo K, Clark ED. A tier approach for evaluating the respiratory allergenicity of low molecular weight chemical Fund Appl Toxicol 1992;18:107-14.

9. Dearman RJ, Basketter DA, Kimber I. Variable effects of chemical allergens on serum IgE concentration in mice. Preliminary evaluation of a novel approach to the identification of respiratory sensitizers. J Appl Toxicol 1992;12:31723.

10. Dearman RJ, Basketter DA, Kimber I. Differential cytokine production following chronic exposure of mice to chemical respiratory and contact allergens. Immunology $1995 ; 86: 545-50$.

11. Zeiss CR, Patterson R, Pruzansky JJ, Miller MM, Rosenberg M, Levitz D. Trimellitic anhydride-induced airway syndromes: clinical and immunologic studies. J Allergy Clin Immunol 1977;60:96-103.

12. Howe $\mathrm{W}$, Venables KM, Topping MD, Dally MB, Hawkins R, Law JS, et al. Tetrachlorophthalic anhydride asthma: evidence for specific IgE antibody. J Allergy Clin Immunol 1983;71:5-11.

13. Nielsen J, Welinder $H$, Schütz A, Skerfving S. Specific serum antibodies against phthalic anhydride in occupationally exposed subjects. J Allergy Clin Immunol 1988;82:126-33.

14. Welinder H, Nielsen J, Gustavsson C, Bensryd I. Specific antibodies to methyltetrahydrophthalic anhydride in exposed workers. Clin Exp Allergy 1990;20:639-45.

15. Welinder H, Zhang XD, Gustavsson C, Björk B, Skerfving $S$. Structure-activity relationships of organic acid anhydrides as antigen in an animal model. Toxicology 1995; 103:127-36.

16. Tada T, Okumura K, Platteau B, Beckers A, Bazin H. Halflives of two types of rat homocytotropic antibodies in circulation and in the skin. Int Arch Allergy Appl Immunol 1975;48:116-31.

17. Sorkness R, Blythe S, Lemanske RF JR. Pulmonary antigen challenge in rats passively sensitized with a monoclonal IgE antibody induces immediate but not late changes in airway mechanics. Am Rev Respir Dis 1988;138:1152-6.

18. Lindh $\mathrm{CH}$, Jönsson BAG. Determination of hexahydrophthalic acid and methylhexahydrophthalic acid in plasma after derivatization with pentafluorobensyl esters using gas chromatography and mass spectrometric detection. J Chromatography 1997;691:331-9.

19 Snyder SL, Sabocinski PZ. An improved 2,4,6-trinitrobenzene sulphonic acid method for the determination of amines.
Anal Biochem 1975;64:284-8.

20. Eberson L, Landström L. Studies on cyclic anhydrides. IV. Rate constants for the hydrolysis of some cyclic anhydrides exhibiting ring strain. Acta Chem Scand 1972;26:239— 49.

21. Topping MD, Venables KM, Luczynska CM, Howe W, Newman Taylor AJ. Specificity of the human IgE response to inhaled acid anhydrides. J Allergy Clin Immunol 1987;77:834-42.

22. Welinder H, Nielsen J. Immunologic tests of specific antibodies to organic acid anhydrides. Allergy 1991;46:601-9.

23. Binaghi RA, Perrudet-Badoux A. Additive activity of IgE and IgG anaphylactic antibodies in rats. Ann Immunol Paris 1976;127:49-56.

24. Yeadon M, Price R. Induction of calcium-independent nitric oxide synthase by allergen challenge in sensitized rat lung in vivo. Br J Pharmacol 1995;116:2545-6.

25. Palacian E, Gonzales MP, Pineiro M, Hernandes F. Dicarboxylic acid anhydrides as dissociating agents of proteincontaining structures. Mol Cell Biochem 1990;97:101-11.

26. Zhang X-D, Lötvall J, Skerfving S, Welinder H. Antibody specificity to chemical structures of organic acid anhydrides studied by in-vitro and in-vivo methods. Toxicology 1997; 118:223-32.

27. Zhang X-D, Lötvall Y, Arahawa H, Welinder H, Skerfving S. Relationship between $\operatorname{IgG}_{1}$ levels and airway responses in guinea pigs actively and passively sensitized to hexahydrophthalic anhydride. Allergy 1998;53:20 -7.

28. Watanabe A, Hayashi H. Allergen-induced biphasic bronchoconstriction in rats. Int Arch Allergy Appl Immunol 1990;11:71-7.

29. Selgrade MJK, Zeiss CR, Karol MH, Sarlo K, Kimber I, Tepper JS, et al. Workshop on status of test methods for assessing potential of chemicals to induce respiratory allergic reactions. Inhalation Toxicol 1994:6:303-19.

30. Zeiss CR, Mitchell JH, Van-Peenen PF, Harris J, Levitz D. A twelve-year clinical and immunologic evaluation of workers involved in the manufacture of trimellitic anhydride (TMA). Allergy Proc 1990;11:71-7.

31. Welinder HE, Jönsson BAG, Nielsen JE, Ottosson HE, Gustavsson CA. Exposure-response relationships in the formation of specific antibodies to hexahydrophthalic anhydride in exposed workers. Scand $\mathrm{J}$ Work Environ Health $1994 ; 20: 459-65$.

Recieved for publication: 27 June 1997 